\title{
Social Norms and Violence Against Children and Youth: Introduction to the Special Issue
}

\author{
J. Bart Klika ${ }^{1}$ J Jeffrey W. Linkenbach ${ }^{2}$
}

Published online: 17 January 2019

(c) Springer Science+Business Media, LLC, part of Springer Nature 2019

Social norms have always been central to the field of public health, as they are to this special issue of the Child and Adolescent Social Work Journal. Norms shape our attitudes, impact our behavior and define who we are-for better or worse. For those of us dedicated to making the world a healthier, safer place to live, social norms matter.

For illustrative purposes, let's look at the issue of smoking. In the not too distant past, smoking was allowed in a wide range of public places, including areas such as restaurants and airplanes. For those of us who spend considerable amounts of our time flying, it is hard to imagine now sitting next to someone actively smoking a cigarette on a turbulent, cross-country flight (*Ironically, as the first author wrote these words sitting in the airport, an overhead message reminded travelers that "smoking was prohibited in the airport terminal"). So, what changed? In her recent book "How Change Happens: Why Some Social Movements Succeed While Others Don't," Crutchfield (2018) examines the qualities and characteristics of successful social movements, including the movement to place bans on smoking in public places. What she found were some of the usual suspects: bottom-up versus a sole focus on top-down strategies; coordinating the momentum of many change agents; viewing change as slow and incremental; and appealing to the heads and hearts of the general public. Ultimately, this combination of factors shifted the societal norms associated with public smoking, creating the ideal climate for policy, and ultimately, behavioral change.

In spite of the United States' progress with public health policy and programs over the past century, youth violence remains rampant. Child abuse, bullying, human trafficking are but a few examples of the ways in which children's

J. Bart Klika

bklika@preventchildabuse.org

1 Prevent Child Abuse America, 228 S. Wabash Ave, Floor 10, Chicago, IL 60604, USA

2 The Montana Institute, Bozeman, MT, USA healthy development is put at risk. Children and youth who are victimized present with elevated levels of mental health problems (Herrenkohl, Hong, Klika, Herrenkohl, \& Russo, 2013), substance abuse (Lansford, Dodge, Pettit, \& Bates, 2010), difficulty in the school setting (Romano, Babchishin, Marquis, \& Frechette, 2014), and engage in more antisocial behavior than their non-victimized peers (Klika, Herrenkohl, \& Lee, 2013). Preventing the early experiences of trauma and adversity that set in motion the cascade of negative outcomes is of tantamount importance for those interested in securing healthy futures for our children.

It is undeniable that children are affected by their social environment. However, the social environment is complex, constantly shifting, and does not represent one single thing. Like a set of nested Russian dolls, the social ecology represents the ways in which individuals are embedded within families or relational contexts, and these family or relational contexts are nested within larger community or neighborhood contexts, and these community or neighborhood contexts are nested within larger socio-political environments (Bronfenbrenner, 1979). To understand and individual, we must understand the multiple, interconnected contexts in which that person is embedded.

The social ecology is instrumental in our thinking about social norms, levels of intervention, and the prevention of violence and neglect with children. Some strategies focus on individuals, others seek to impact the family or relational context, while others work to address the community contexts where children and families live. Finally, at the outer levels of the social ecology sits the socio-political and cultural factors that can have profound effects on shaping risk and protective factors for children and families. Examples of socio-political factors include social policies, and, the focus of this special issue, the societal norms and mores that dictate culturally acceptable and unacceptable behavior.

As noted by Davis, Fujie-Parks, and Cohen (2006),

norms are one of the most powerful societal and com-

munity influences in shaping behavior. They are regu- 
larities in behavior with which people generally conform, and they foster disapproval of deviance. More than a habit, norms are often based in culture and tradition. They are our attitudes, beliefs, and standards that we take for granted. In other words, norms are behavior shapers. They are the way in which the environment tells people what is ok and not ok (p. 4).

It is clear that social norms (both perceived and actual) are strong drivers of human behavior, but how does knowing something about social norms influence our scientific understanding of preventing violence against children and youth? Changing social norms that accept, support, or allow indifference to any forms of violence is critical to the prevention of child abuse and neglect. In addition to changing more obvious norms related to behaviors, the science of social norms also impacts the less observable factors like changing the way we think and talk about why child abuse and neglect occurs and the focus of responsibility for preventing it (our public narrative). Social norms impact the way we think, talk, and act regarding child abuse and neglect, and this context is foundational for framing scientific research and the use of science-based evidence to inform policy choices and programs to impact norms change.

The articles included in this special issue of the Child and Adolescent Social Work Journal add to the body of literature around the topic of social norms associated with violence against children. Klika, Haboush-Deloye, and Linkenbach (2019) present data from a large national survey and a state-wide survey to describe social norms regarding the seriousness and preventability of child abuse and neglect as well as self-reported and perceived willingness to intervene on behalf of children and families. These surveys further explored whether social norms associated with child physical abuse, neglect, and sexual abuse differed by key sub-groups. Results indicate that the general public shares concern regarding the issue of child maltreatment yet lacks the knowledge on how to intervene on behalf of children and families. The authors discuss implications of these findings for creating social norms messaging campaigns to promote positive norms and to shift negative or misperceived norms.

Krugman and Poland (2019) provide a commentary on the state of the child maltreatment field and the development of the recently formed National Foundation to End Child Abuse and Neglect (EndCAN). As the authors' note, the goals of EndCAN are twofold: (1) shift social norms to view child maltreatment as a health, mental health and ultimately, public health problem, not just a social and legal problem, and (2) coordinate and financially support research, prevention, training, and advocacy in service of shifting the way we support children and families.

Using a nationally representative opt-in internet panel, Klevens et al. (2019) explored social norms associated with the use of corporal punishment among Black, Latino, and White parents. Drawing on quantitative survey data as well as qualitative focus group data, the authors document the frequency of self-reported and perceived spanking among the sample. Further, quantitative and qualitative analyses explored normative differences among racial/ethnic groups, providing direction for future research and social norms messaging.

Also on the topic of corporal punishment, a known risk factor for child physical abuse, Fleckman, Taylor, Theall, and Andrinopoulos (2019) examined the role of perceived social norms and collective efficacy on attitudes towards and self-reported use of corporal punishment using a sample of low-income women in the greater New Orleans region. Results show that perceived injunctive norms are a strong driver of corporal punishment and the authors suggest directions for altering normative beliefs through communitybased social norms campaigns.

Vaughan-Eden, Holden, and LeBlanc (2019) provide a general commentary on the topic of corporal punishment, drawing on the key themes outlined by Klevens et al. (2019) and Fleckman et al. (2019). In their commentary, the authors describe the historical landscape of initiatives to reduce and ban corporal punishment, including a current national movement to end the hitting of children. In closing, the authors describe the practice and science behind an emerging approach, No-Hit-Zones, in eliminating corporal punishment in public settings.

Finigan-Carr, Johnson, Pullmann, Stewart, and Fromknecht (2019) outline an ecologically-informed framework for sex trafficking prevention. In their framework, the authors highlight the societal, political, cultural, normative, relational, and personal factors which increase a child's vulnerability to sex trafficking. As the authors note, these ecological factors are complex and interact in with one another at multiple levels of the social ecology simultaneously. In closing, the authors provide guidance for research, practice, policy and social norms change related to child sex trafficking.

Gomez and Fliss (2019) describe three federally funded, community-based projects, which are working to change the normative contexts in which children and families live and engage. The work with the Yakima Valley Farm Workers Clinic, Kentucky Cabinet for Health and Family Services, and the Massachusetts Children's Trust Fund reminds readers that solutions to complex problems such as child maltreatment, already exist within communities. The goal of our work then must shift towards identifying the positive norms that already exist within communities and to work on strengthening and promoting those norms that support children and families.

Linkenbach et al. (under review) evaluate the impact of the Positive Community Norms (PCN) approach in correcting high school student perceptions of alcohol use norms 
and decreasing use of alcohol in ten communities across the state of Minnesota. After a 5-year implementation of the PCN approach, results suggest that organizing strategies to affect changes in social norms regarding alcohol use are associated with changes in rates of alcohol use. The authors provide suggestions for future research and implementation of community-based strategies like the PCN approach.

The scientific foundation of public health is to turn social science into social action in order to drive public policies, campaigns, programs and interventions to achieve positive results at a population level. Plainly stated, social norms create context-including scientific context, impacting the way we think, talk and frame research questions to inform policy choices and programs. Like all science-based public health research, the focus on impacting norms related to violence build from a core assumption and the critical role of sound science; mainly, if we can predict it—we can prevent it. This special issue of the Child and Adolescent Social Work Journal seeks to add science to help us predict and prevent child abuse and neglect by increasing our understanding of the role of social norms.

\section{Compliance with Ethical Standards}

Conflict of interest The authors declare they have no conflict of interest.

Research Involving Human and Animal Participants This article does not contain any studies with human participants or animals performed by any of the authors.

\section{References}

Bronfenbrenner, U. (1979). The ecology of human development: Experiments by nature and design. Cambridge, MA: Harvard University Press.

Crutchfield, L. R. (2018). How change happens: Why some social movements succeed while others don't. Hoboken, NJ: Wiley

Davis, R., Fujie-Parks, L., \& Cohen, L. (2006). Sexual violence and the spectrum of prevention: Towards a community solution. National Sexual Violence Resource Center. Retrieved from https://www. preventioninstitute.org/sites/default/files/publications/Sexual $\% 20$ Violence\%20Spectrum.pdf.
Finigan-Carr, N. M., Johnson, M. H., Pullmann, M. D., Stewart, C. J., \& Fromknecht, A. E. (2019). A traumagenic social ecological framework for understanding and intervening with sex trafficked children and youth. Child \& Adolescent Social Work Journal. https://doi.org/10.1007/s10560-018-0588-7.

Fleckman, J., Taylor, C. A., Theall, K. P., \& Andrinopoulous, K. (2019). Perceived social norms in the neighborhood context: The role of perceived collective efficacy in moderating the relation between perceived injunctive norms and use of corporal punishment. Child \& Adolescent Social Work Journal. https://doi. org/10.1007/s10560-018-0581-1.

Gomez, R., \& Fliss, J. (2019). A community-based prevention approach: Examples from the field. Child \& Adolescent Social Work Journal. https://doi.org/10.1007/s10560-018-0593-X.

Herrenkohl, T. I., Hong, S., Klika, J. B., Herrenkohl, R. C., \& Russo, M. J. (2013). Developmental impacts of child abuse and neglect related to adult mental health, substance use, and physical health. Journal of Family Violence, 28, 191-199.

Klevens, J., Mercer-Kollar, L., Rizzo, G., O’Shea, G., Nguyen, J., \& Roby, S. (2019). Commonalities and differences in social norms related to corporal punishment among Black, Latino, and White parents. Child \& Adolescent Social Work Journal. https://doi. org/10.1007/s10560-018-0591-z.

Klika, J. B., Haboush-Deloye, A., \& Linkenbach, J. (2019). Hidden protections: Identifying social norms associated with child abuse, sexual abuse, and neglect. Child \& Adolescent Social Work Journal.

Klika, J. B., Herrenkohl, T. I., \& Lee, J. O. (2013). School factors as moderators of the relationship between physical child abuse and pathways of antisocial behavior. Journal of Interpersonal Violence, 28, 852-867.

Krugman, R. D., \& Poland, L. (2019). Disrupting social norms: Eliminating child abuse and neglect in our lifetime. Child \& Adolescent Social Work Journal. https://doi.org/10.1007/s10560-018-0589-6.

Lansford, J. E., Dodge, K. A., Pettit, G. S., \& Bates, J. E. (2010). Does physical abuse in early childhood predict substance use in adolescence and early adulthood. Child Maltreatment, 15, 190-194.

Linkenbach, J., Bengtson, P., Brandon, J., Fredrickson, A., Kilmer, J., Lubbers, D., ... Thompson, S. (under review). Reduction of youth 30-day alcohol use using the Positive Community Norms approach: A five-year Minnesota intervention. Child \& Adolescent Social Work Journal.

Romano, E., Babchishin, L., Marquis, R., \& Frechette, S. (2014). Childhood maltreatment and educational outcomes. Trauma, Violence, \& Abuse, 16, 418-437.

Vaughan-Eden, V., Holden, G. W., \& LeBlanc, S. L. (2019). Changing the social norm about corporal punishment. Child \& Adolescent Social Work Journal. https://doi.org/10.1007/s10560-018-0592-y.

Publisher's Note Springer Nature remains neutral with regard to jurisdictional claims in published maps and institutional affiliations. 